\title{
One week's anti-Helicobacter pylori treatment for duodenal ulcer
}

\author{
R P H Logan, P A Gummett, J J Misiewicz, Q N Karim, M M Walker, J H Baron
}

\begin{abstract}
This open study tested whether eradication of Helicobacter pylori (H pylori) heals duodenal ulcers as well as decreasing recurrence. $H$ pylori was detected in patients with endoscopic duodenal ulcers by histology, CLOtest, culture, and ${ }^{13} \mathrm{C}$-urea breath test $\left({ }^{13} \mathrm{C}\right.$ UBT). Tripotassium dicitrato bismuthate (120 $\mathrm{mg}$ ) and amoxycillin (500 $\mathrm{mg}$ ) each four times daily, were given for seven days, with $400 \mathrm{mg}$ metronidazole five times a day on days 5-7. The ${ }^{13} \mathrm{C}$-UBT was repeated immediately after treatment and endoscopy repeated within 21 days. After treatment unhealed ulcers were reinspected one month later and healed ulcers followed up by ${ }^{13} \mathrm{C}$-UBT alone for 12 months. Of 45 patients, 44 were available for follow up. Mean pretreatment excess $\delta^{13} \mathrm{CO}_{2}$ excretion was 25.6 per mil, which fell to 2.4 per mil immediately after finishing treatment, indicating clearance of $H$ pylori in every patient. At the second endoscopy (median interval 20 days from start of treatment) 33 of 44 (75\%) duodenal ulcers had healed. Ten of the remaining 11 duodenal ulcers were smaller and those $\mathbf{1 0}$ healed in the next two weeks with no further treatment. Two patients' ulcers that initially healed with clearance of $H$ pylori recurred three weeks later (both had metronidazole resistant $\boldsymbol{H}$ pylori). $\boldsymbol{H}$ pylori was eradicated in 28 of $44(64 \%)$ patients $\left({ }^{13} \mathrm{C}\right.$-UBT negative for median follow up 10.2 months). Overall 41 of 43 (93\%, 95\% confidence intervals 81\%-99\%) duodenal ulcers were healed at one month. This study suggests that one week of anti$H$ pylori triple treatment is effective in healing duodenal ulcers.

(Gut 1994; 35: 15-18)
\end{abstract}

Helicobacter pylori ( $H$ pylori) causes nonautoimmune gastritis ${ }^{1}$ and is one important factor in the aetiology of recurrent duodenal ulcer. ${ }^{2}$ Thus recurrence of $H$ pylori precedes ulcer recurrence, ${ }^{3}$ the density of antral $H$ pylori increases the rate of ulcer recurrence ${ }^{4}$ and successful eradication of $H$ pylori after duodenal ulcer healing substantially prevents recurrence. ${ }^{5-7}$ All of these studies, however, focused on the role of $H$ pylori in recurrence of duodenal ulcers rather than on primary ulcer healing. We have previously developed a novel one week triple treatment that eradicated $93 \%$ of metronidazole sensitive $H$ pylori. ${ }^{8}$ We have now for the first time investigated healing of duodenal ulcers with this regimen as the sole primary treatment.

Correspondence to: Dr R P H Logan, Departmen of Gastroenterology and Nutrition, Central Middlesex Hospital, Acton Lane, Park Royal, London NW10 7NS. Accepted for publication 19 May 1993
Patients and methods

After routine diagnostic endoscopy of the upper gastrointestinal tract patients with a duodenal ulcer greater than $5 \mathrm{~mm}$ in diameter were invited to enter and give written consent to the study, which was approved by the Parkside ethics committee. Patients with previous gastric surgery, known bleeding diathesis, taking oral anticoagulants, or who had been treated in the previous two months with bismuth compounds or antibiotics known to be active against $H$ pylor were excluded. Patients taking $\mathrm{H}_{2}$ antagonists, proton pump inhibitors, or whose ulcers had recently bled were not excluded.

Endoscopes were disinfected with an automatic washing machine (Olympus EW20) ${ }^{9}$ after each examination and the biopsy forceps were sterilised by autoclaving.

\section{ASSESSMENT OF H PYLORI STATE}

The presence of $H$ pylori was assessed by the ${ }^{13} \mathrm{C}$ urea breath test $\left({ }^{13} \mathrm{C}\right.$-UBT), histological examination of two antral biopsy specimens, CLO-test (Delta West Ltd, Western Australia), and culture (two antral biopsies, selective and nonselective media, microaerophobic conditions for up to 10 days). Tests for metronidazole sensitivity $(5 \mu \mathrm{g})$ were completed by an in vitro disc method (mast sensitivity discs, Mast Laboratories, Liverpool). Metronidazole resistant or metronidazole sensitive $H$ pylori are subsequently referred to as MR $H$ pylori and MS $H$ pylori, respectively.

Patients were classified as $H$ pylori positive by a positive ${ }^{13} \mathrm{C}$-UBT and CLO-test together with positive histology or culture. Clearance of $H$ pylori was defined as a negative ${ }^{13} \mathrm{C}$-UBT at the end of treatment. Eradication was defined as a negative ${ }^{13} \mathrm{C}$-UBT one month after the end of treatment (negative ${ }^{13} \mathrm{C}$-UBT $=$ excess $\delta^{13} \mathrm{CO}_{2}$ excretion $<5$ per mil $).^{10}$

\section{${ }^{13}$ C-UREA BREATH TEST}

The ${ }^{13} \mathrm{C}$-UBT (European standard protocol) ${ }^{10}$ was completed within 24 hours of the initial endoscopy in all patients. Briefly, a baseline sample of expired breath was obtained before ingesting a fatty liquid test meal to delay gastric emptying. After 10 minutes, $100 \mathrm{mg}{ }^{13} \mathrm{C}$-urea (99\% pure, Cambridge Isotopes, Boston, USA) in $50 \mathrm{ml}$ of tap water was swallowed and distributed within the stomach by turning the patient to the left and right decubitus position. Two litre serial breath samples were collected every five minutes into a large reservoir collecting bag, from which a single $20 \mathrm{ml}$ sample was taken at the end of the test and analysed by mass spectrometry (BSIA, Brentford, London). A positive result was defined as excess $\delta^{13} \mathrm{CO}_{2}$ excretion $>5$ per mil, as determined from previous studies. ${ }^{10}$

Patients with a positive ${ }^{13} \mathrm{C}$-UBT and positive 


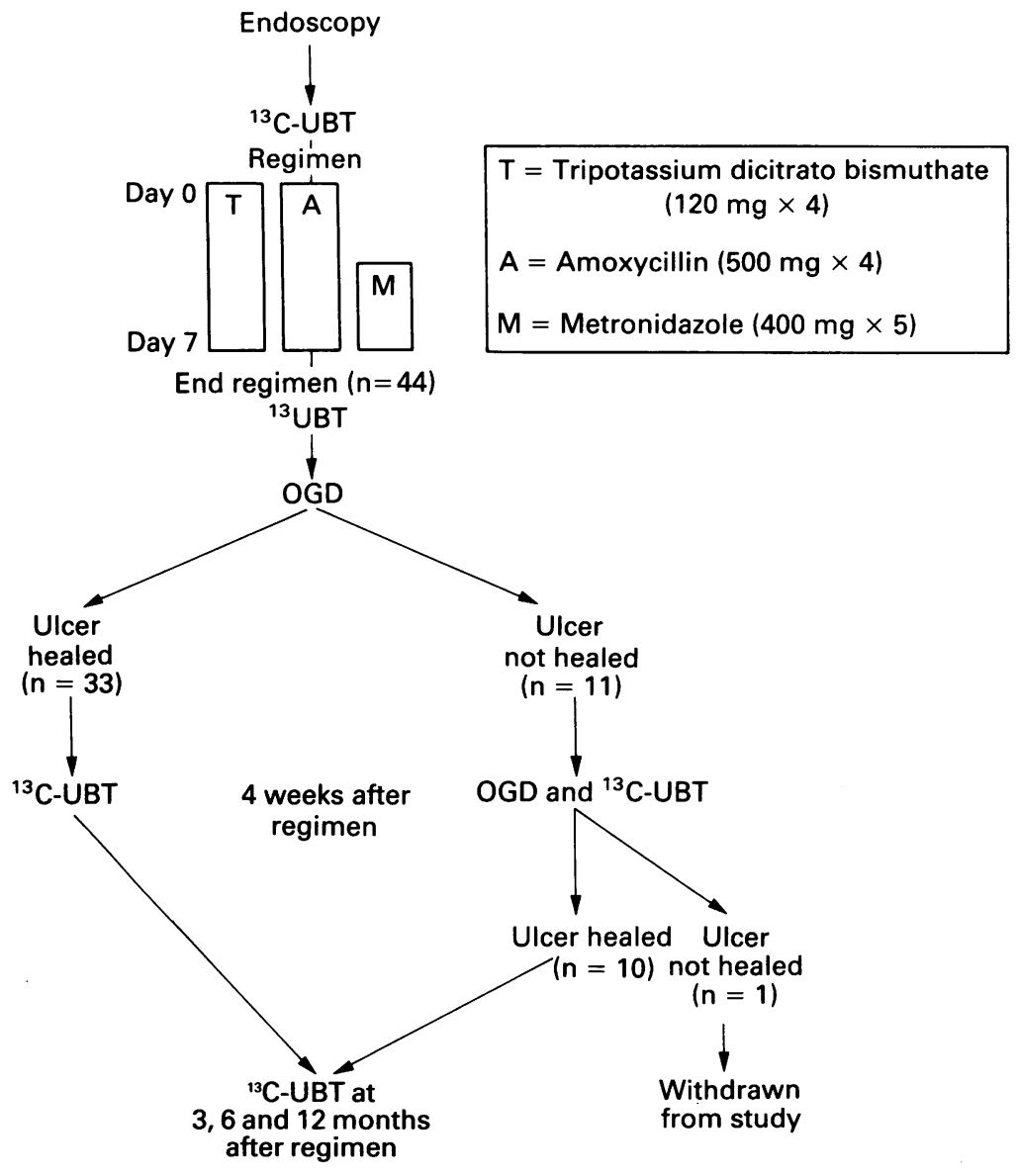

Outline of study design with the number of patients with healed ulcers at first or second follow up. $O G D=$ endoscopy.

CLO-test were given $120 \mathrm{mg}$ tripotassium dicitrato bismuthate and $500 \mathrm{mg}$ amoxycillin, each four times a day, for seven days (days 1-7). Metronidazole ( $400 \mathrm{mg}$ ) was given five times a day for the last three days (days 5-7). This high dose was used to decrease the risk of promoting the development of MR $H$ pylori.

\section{FOLLOW UP}

Immediately after the end of eradication treatment, a second ${ }^{13} \mathrm{C}$-UBT was performed to assess clearance (to determine the effectiveness of treatment), followed as soon as possible by a second endoscopy to assess ulcer healing. In those patients with healed ulcers further ${ }^{13} \mathrm{C}$-UBTs were done at one, three, six, and 12 months: they were re-endoscoped only if ulcer symptoms recurred. Patients whose ulcer had not healed were again endoscoped and had a ${ }^{13} \mathrm{C}$-UBT one month after the end of eradication treatment. If the ulcer was healed, they had further ${ }^{13} \mathrm{C}$-UBTs at three, six, and 12 months (Figure).

Ulcer healing and relapse, metronidazole sensitivity, and eradication

\begin{tabular}{llllll}
\hline & $\begin{array}{l}\text { H pylori } \\
\text { cleared }\end{array}$ & $\begin{array}{l}\text { Ulcer healed } \\
\text { at first } \\
\text { follow up }\end{array}$ & $\begin{array}{l}\text { H pylori } \\
\text { eradicated }\end{array}$ & $\begin{array}{l}\text { Ulcer healed } \\
\text { only at one } \\
\text { month }\end{array}$ & $\begin{array}{l}\text { Ulcer } \\
\text { recurred or } \\
\text { unhealed }\end{array}$ \\
\hline No of patients & 23 & 15 & 20 & 8 & 0 \\
MS H pylori (23) & 12 & 12 & 2 & 0 & 2 \\
$\begin{array}{l}\text { MR H pylori(12) } \\
\text { M sensitivity not } \\
\text { known (9) }\end{array}$ & 9 & 6 & 6 & 2 & 2 \\
Total (44) & 44 & 33 & 28 & 10 & 4 \\
\hline
\end{tabular}

Patients who failed to clear $H$ pylori after treatment, or whose ulcers failed to heal, or who had recurrent $H$ pylori at one month were not studied further.

Confidence intervals on proportions are based on the binomial distribution.

\section{Results}

The Figure shows the study design. The Table summarises ulcer healing and relapse, metronidazole sensitivity, and eradication data.

\section{PATIENTS}

Forty five patients (27 men, median age 37, range 17-76 years) with duodenal ulcers $(>5 \mathrm{~mm})$ and $H$ pylori were entered into the study; 44 are available for follow up. The remaining patient declined further endoscopy and follow up because he had no symptoms. Twenty two patients were smokers, five presented with either haematemesis or melaena, of whom three had been started on $\mathrm{H}_{2}$ antagonists within 24 hours of the initial endoscopy, and a further three patients had duodenal ulcers resistant to standard treatment: $300 \mathrm{mg}$ ranitidine at night $(n=1), 400 \mathrm{mg}$ cimetidine twice a day $(\mathrm{n}=1)$, or $40 \mathrm{mg}$ omeprazole in the morning $(n=1)$, each for one month. Any treatment with $\mathrm{H}_{2}$ antagonists or proton pump inhibitor was stopped within 24 hours of the initial endoscopy in all patients.

\section{ENDOSCOPY}

At the second endoscopy 33 of $44(75 \%, 95 \%$ confidence intervals (95\% CI) $60 \%-87 \%$ ) ulcers were completely healed, 10 of the remaining 11 were smaller (median diameter $3 \mathrm{~mm}$ ), and one was larger. The median interval between the end of treatment and the second endoscopy was 13 days (range 1-31 days, variation due to missed appointments and holidays).

One month after the end of treatment 10 of the initially unhealed 11 ulcers had healed completely without any further treatment in the intervening three weeks. The remaining ulcer had increased in size (MR $H$ pylori). Two patients whose ulcers initially healed (both infected with MR $H$ pylori) had an early symptomatic ulcer recurrence, which was confirmed at endoscopy three weeks after the end of treatment. Thus overall 43 of 44 (98\%) duodenal ulcers healed after the one week $H$ pylori eradication regimen, with 41 of 44 (93\%, 95\% CI 81\%$99 \%)$ still healed at one month.

\section{H PYLORI AND METRONIDAZOLE SENSITIVITY} All 44 patients were colonised by $H$ pylori as detected by a positive ${ }^{13} \mathrm{C}$-UBT and positive antral histology. The ${ }^{13} \mathrm{C}$-UBT became negative in all 44 patients immediately after finishing treatment indicating that the treatment regimen had cleared $H$ pylori in every patient. $H$ pylori was grown from 38 of 44 patients and metronidazole sensitivity established in 35: $12(34 \%)$ isolates were resistant and $23(66 \%)$ were sensitive to metronidazole. In these 23 patients the 
ulcers were healed at one month or earlier in 20 of $23(87 \%, 95 \%$ CI $60 \%-95 \%)$ (Table), with neither recurrent symptoms nor recurrence of $H$ pylori during subsequent follow up (median $=$ 10 , range 6-14 months). In the 12 patients with pretreatment MR $H$ pylori duodenal ulcer healing was achieved in all 12 , but $H$ pylori was eradicated in only two of $12(17 \%)$.

\section{FOLLOW UP}

Overall $H$ pylori was eradicated in 28 of 44 patients $(64 \%, 95 \%$ CI $48 \%-76 \%)$. In these patients there was no evidence by ${ }^{13} \mathrm{C}$-UBT of recurrent $H$ pylori at three and six months and no recurrence of ulcer symptoms during this period of follow up. In the other 16 patients the ${ }^{13} \mathrm{C}$ UBT became positive indicating failed eradication: in these 16 with persistent $H$ pylori, one duodenal ulcer had not healed at one month follow up, two had recurrent ulcers within three weeks of finishing treatment, and five had recurrent dyspepsia but no recurrent ulcers on repeat endoscopy.

\section{Discussion}

For many years the treatment of duodenal ulcer has been based on Schwartz's dictum 'no acid no ulcer', and whereas this is remarkably successful with $90 \%-100 \%$ duodenal ulcer healing within two months of antisecretory treatment, there is a disappointingly high rate of ulcer recurrence on stopping treatment - $50 \%$ can recur within six months. "It is now clear that acid inhibitors do not change the natural history of the underlying ulcer diathesis. The natural history can be changed, however, by eradication of $H$ pylori, which decreases the incidence of ulcer recurrence. $^{5-7}$

Previous studies of duodenal ulcer and $H$ pylori (with comparatively lengthy treatment regimens of antibiotics in conjunction with either bismuth salts, or antisecretory agents) have focused on recurrence of $H$ pylori and relapse to duodenal ulcers, ${ }^{5-7}$ whereas all the studies of duodenal ulcer healing with bismuth monotherapy were done before the discovery of H pylori.

\section{ULCER HEALING}

This study is the first to examine the alternative strategy of using an anti- $H$ pylori regimen as the primary (and only) treatment for healing duodenal ulcers. On an intention to treat basis $75 \%$ of duodenal ulcers healed on the seven day $H$ pylori eradication regimen. Ulcer healing was not complete in 11 patients at the first follow up endoscopy (median interval from the end of treatment nine days). Further treatment was not needed and 10 of 11 duodenal ulcers healed completely within 28 days, or earlier, after finishing eradication treatment, achieving a 93\% healing rate at one month after the end of the regimen.

This open pilot study was uncontrolled, but the results are comparable with a recent two week trial of $20 \mathrm{mg}$ omeprazole in the morning $v$ $150 \mathrm{mg}$ ranitidine twice daily with two week healing rates of $86 \%$ and $63 \%$ respectively. ${ }^{12}$

\section{BISMUTH}

There are no studies of the rate of duodenal ulcer healing with bismuth salts after less than four weeks of treatment ${ }^{13-15}$ and it is possible that the $75 \%$ healing rate could have been due to the bismuth in our triple treatment regimen. In studies with bismuth salts as the sole agent, healing and prevention of recurrence may have been promoted by the anti- $H$ pylori, mucosal protective, or other properties of accumulated bismuth. Bismuth monotherapy can heal duodenal ulcers without inhibition of acid secretion, ${ }^{13} 15$ but it is not clear whether the benefit is due to suppression of $H$ pylori or other mechanisms - for example, decreasing pepsin. ${ }^{16}$ Eradication rates with bismuth salts alone, however, are very low. ${ }^{17}$

\section{H PYLORI}

Although many workers are at present attempting to identify pathogenic factors characterising strains of $H$ pylori associated with duodenal ulcers, ${ }^{18-21}$ our study suggests that regardless of pathogenicity, the overall load of the organism may be important in determining the clinical outcome. Thus in two patients duodenal ulcers healed after suppressing $H$ pylori to a low level of infection (excess $\delta^{13} \mathrm{CO}_{2}$ excretion $1 \cdot 3$ and $2 \cdot 1$ per mil for each patient at the end of treatment). Within days of finishing treatment the level of infection, as measured by the ${ }^{13} \mathrm{C}$-UBT, had returned to pretreatment levels: this was followed by ulcer recurrence 10 days later.

\section{METRONIDAZOLE SENSITIVITY}

Duodenal ulcers healed in all the 23 patients infected with MS $H$ pylori. In 20 of these 23 patients $H$ pylori was eradicated and neither ulcer nor $H$ pylori had recurred within the nine months of follow up. The ulcers also healed in the 12 patients with MR $H$ pylori, but $H$ pylori was eradicated in only two of 12 . Although those patients with persistent $H$ pylori are at risk of duodenal ulcers, symptomatic ulcer recurrence has so far not occurred in any patient. Recurrence without symptoms is possible but could be delayed, as seen after bismuth monotherapy, ${ }^{14} 15$ which generally only suppresses $H$ pylori. ${ }^{17}$

We and others have shown that the most important factor in preventing recurrent duodenal ulcer is the success of the treatment regimen in eradicating $H$ pylori. Previous studies suggest that any regimen that includes metronidazole will not work if the stomach is infected with MR $H$ pylori. ${ }^{821} 22$ The design of this study prevented the exclusion of patients with $M R$ $H$ pylori and this is the most likely reason for the low overall eradication rate. For optimal management strategy, routine in vitro antibiotic sensitivity tests are desirable before attempting to eradicate $H$ pylori, in order to treat patients with drugs that are likely to be successful against their bacteria and to prevent the emergence of resistant strains. 
Although no formal symptom assessments were made in this study, no patient needed additional treatment after their initial one week eradication regimen, including the patients with unhealed ulcers at the first follow up endoscopy.

The main conclusion of this study is that one week's triple treatment (which had been shown to be highly effective in eradicating $H$ pylori) is highly effective in healing duodenal ulcers. Ulcer healing is probably, but not certainly, due to clearance of $H$ pylori rather than to other effects of the bismuth, amoxycillin, or metronidazole. The ulcers that healed after clearance of $H$ pylor $i$ all remained healed during the period of follow up if the $H$ pylori had been eradicated, but two of those whose $H$ pylori had been cleared but not eradicated recurred during follow up.

This approach to duodenal ulcer healing poses new problems, particularly that of MR $H$ pylori. Anti- $H$ pylori regimens containing metronidazole will not be successful in areas where the incidence of MR $H$ pylori is high. ${ }^{22}$ Further studies, including symptom assessments and follow up endoscopy in all patients are needed, before the proper place of this strategy in the management of duodenal ulcer can be established.

We thank the endoscopy staff at the Central Middlesex and St Mary's Hospitals and Luke Whitaker for their help with this study. Dr R Logan was supported by a grant from Glaxo Group Research.

An abstract of this study was presented to British Society of Gastroenterology in September 1991.

1 Rauws EA, Langenberg W, Houthoff HJ, Zanen HC, Tytgat GNJ. Campylobacter pyloridis-associated chronic active antral gastritis. A prospective study of its prevalence and the effects of antibacterial and antiulcer treatment. Gastroenterology 1988; 94: 33-40.

2 Axon AR. Duodenal ulcer: the villain unmasked? BMF 1991; 302: 919-21.

3 Logan RPH, Gummett PA, Polson RJP, Walker MM, Baron JHB, Misiewicz JJ. The recurrence of Helicobacter pylori in relation to duodenal ulcer. Rev Esp Enferm Dig 1990; 78 (suppl 1): 72 .
4 Hui WM, Ho J, Lam SK. Pathogenic role of Helicobacter pylori in duodenal ulcer disease. Dig Dis Sci 1991; 36: 424 30.

5 Marshall BJ, Goodwin CS, Warren JR, et al. A prospective double-blind trial of duodenal ulcer relapse after eradication of Campylobacter pylori. Lancet 1988; 2: 1437-42.

6 Coghlan JG, Humphries H, Dooley C, et al. Campylobacter pylori and recurrence of duodenal ulcers - a 12-month follow-up study. Lancet 1987; ii: 1109-11.

7 Rauws EAJ, Tytgat GNJ. Cure of duodenal ulcer with eradication of Helicobacter pylori. Lancet 1990; 335: 1233-5.

8 Logan RPH, Gummett PA, Misiewicz JJ, et al. A one week eradication regime for Helicobacter pylori. Lancet 1991; 338: 1249-52.

9 Weller IVD, Williams CB, Jeffries DJ, et al. Cleaning and disinfection of equipment for gastrointestinal flexible endoscopy: interim recommendations of a Working Party of the scopy: interim recommendations of a Working Party of the

10 Logan RPH, Dill S, Bauer FE, et al. The European ${ }^{13} \mathrm{C}$-urea breath test for the detection of Helicobacter pylori. European breath test for the detection of Helicobacter pylori. European
fournal of Gastroenterology and Hepatology 1991; 3: 905-11.

Fournal of Gastroenterology and Hepatology 1991; 3: 905-11.
11 Thomas JM, Misiewicz JJ. Histamine $\mathrm{H}_{2}$ antagonists in the short and longterm treatment of duodenal ulcer. Clinics in Gastroenterology 1984; 13: 501-4.

12 Hui WM, Lam SK, Ho J, et al. Effect of omeprazole on duodenal ulcer-associated antral gastritis and Helicobacter pylori. Dig Dis Sci 1991; 36: 577-82.

13 Moshal MG. The treatment of duodenal ulcers with TDB: a duodenoscopic double-blind cross-over investigation. Postgrad Med F 1975; 51 (suppl 5): 36-40.

14 Martin DF, Hollanders D, May SJ, et al. Difference in relapse rates of duodenal ulcer healing with cimetidine or trirates of duodenal ulcer healing with cimetidine

15 Lee FI, Samloff IM, Hardman J. Comparison of Tripotassium dicitrato bismuthate tablets with ranitidine in healing and dicitrato bismuthate tablets with ranitidine in healing
relapse of duodenal ulcers. Lancet 1985; 290: 1299-302.

16 Sidebotham RL, Batten JJ, Li K, Spencer J, Baron JH. Some effects of tripotassium dicitrato bismuthate on gastric secretion and the mucus barrier. Aliment Pharmacol Therap 1990; 4: $535-46$.

17 Logan RPH, Polson RJ, Baron JH, Misiewicz JJ. Follow-up after anti-Helicobacter pylori treatment. Lancet 1991; 37: $562-3$.

18 Figura $\mathrm{N}$, Guglielmetti A, Rossolini A, et al. Cytotoxin production by Campylobacter pylori strains isolated from patients with peptic ulcers and from patients with chronic gastritis only, f Clin Microbiol 1989; 27: 225-6.

19 Cover TL, Dolley CP, Blaser MJ. Characterisation of and human serological response to proteins in Helicobacter pylori broth culture supernatants with vacuolising cytotoxin pylori broth culture supernatants with vacu

20 Crabtree JE, Taylor JD, Wyatt JI, et al. Mucosal IgA recognition of Helicobacter pylori $120 \mathrm{kDa}$ protein, peptic ulceration, and gastric pathology. Lancet 1991; 338: 332-5.

21 Lee A. H pylori initiated ulcerogenesis: look to the host. Lancet 1993; 341: 280-1.

22 Glupczynski Y, Burette A. Drug therapy for Helicobacter pylori infection: Problems and pitfalls. Am $\mathcal{F}$ Gastroenterol 1990; 85: 1545-51.

23 Glupczynski Y, Burette A, De Koster E, et al. Metronidazole resistance in Helicobacter pylori. Lancet 1990; 335: 976-7. 